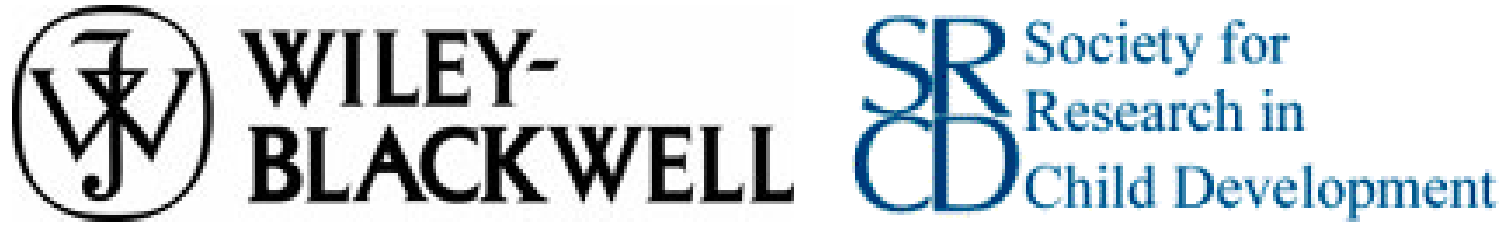

Genetic and Environmental Influences on Temperament in Middle Childhood: Analyses of Teacher and Tester Ratings

Author(s): Stephanie Schmitz, Kimberly J. Saudino, Robert Plomin, David W. Fulker, J. C. DeFries

Source: Child Development, Vol. 67, No. 2 (Apr., 1996), pp. 409-422

Published by: Blackwell Publishing on behalf of the Society for Research in Child Development

Stable URL: http://www.jstor.org/stable/1131823

Accessed: 24/08/2011 15:22

Your use of the JSTOR archive indicates your acceptance of the Terms \& Conditions of Use, available at http://www.jstor.org/page/info/about/policies/terms.jsp

JSTOR is a not-for-profit service that helps scholars, researchers, and students discover, use, and build upon a wide range of content in a trusted digital archive. We use information technology and tools to increase productivity and facilitate new forms of scholarship. For more information about JSTOR, please contact support@jstor.org. 


\title{
Genetic and Environmental Influences on Temperament in Middle Childhood: Analyses of Teacher and Tester Ratings
}

\author{
Stephanie Schmitz \\ University of Colorado, Boulder
}

\section{Kimberly J. Saudino and Robert Plomin}

The Pennsylvania State University

\author{
David W. Fulker and J. C. DeFries \\ University of Colorado, Boulder
}

\begin{abstract}
Schmitz, Stephanie; Saudino, Kimberly J.; Plomin, Robert; Fulker, David W.; and DeFries, J. C. Genetic and Environmental Influences on Temperament in Middle Childhood: Analyses of Teacher and Tester Ratings. CHILd DevelopmENT, 1996, 67, 409-422. Parent ratings of temperament in infancy and childhood yield evidence for genetic influence in twin studies but not in adoption studies. The present study used the sibling adoption design to investigate teacher and tester ratings of temperament in middle childhood. When each child was 7 years old, ratings on the Colorado Childhood Temperament Inventory were obtained from a teacher and tester for more than 50 pairs each of adoptive and nonadoptive siblings in the Colorado Adoption Project. Significant genetic influence emerged for both teacher and tester ratings of Activity, for tester ratings of Sociability, and for teacher ratings of Emotionality. Results obtained from bivariate genetic analysis suggest that the modest covariance between teacher and tester ratings of Activity is entirely mediated genetically. Except for teacher ratings of Attention Span, evidence of shared family environment was nonsignificant, despite the power of the sibling adoption design to detect it.
\end{abstract}

\section{Introduction}

The evidence for genetic influence on temperament in childhood largely comes from twin studies using parental ratings (Plomin, 1986). However, the first parentoffspring and sibling adoption study of parental ratings of temperament found no evidence for genetic influence from 1 to 7 years of age (Plomin, Coon, Carey, DeFries, \& Fulker, 1991). It is possible that the dramatically discrepant results for twin and adoption studies are due to nonadditive genetic variance, that is, interaction between genes, which are shared completely by identical twins but to lesser extents by parents and offspring and by siblings. Thus, if nonadditive genetic variance for a character is substantial, significant genetic influence may be detected in twin studies, but not in parentoffspring or sibling studies in which nonadditive genetic variance plays a lesser role. Another possibility is that parents might exaggerate the resemblance of identical twins or the differences between fraternal twins (Plomin, Chipuer, \& Loehlin, 1990). In support of this hypothesis is the finding that identical twin correlations for parental ratings of temperament are about .60, whereas fraternal twin correlations are near zero (Buss \& Plomin, 1984; Stevenson \& Fielding, 1985).

This research was supported by grants HD-10333 and HD-18426 from the National Institute of Child Health and Human Development, and by grant MH-43899 from the National Institutes of Mental Health. The analyses were facilitated by BRSG Grant RR-07013-25 awarded to the University of Colorado by the Biomedical Research Support Grant Program, Division of Research Resources, National Institutes of Health. The article was written while the first author was supported in part by Grant HD-07289 from NICHD and the second author was funded by a postdoctoral fellowship awarded by the Social Sciences and Humanities Research Council of Canada. The authors wish to thank the four anonymous reviewers for their comments. Mailing address: Stephanie Schmitz, Institute for Behavioral Genetics, Campus Box 447, University of Colorado, Boulder, CO 80309-0447; e-mail: schmitzs@ibg.Colorado.edu. 
These problems suggest the need to investigate the etiology of individual differences in temperament using measures other than parental ratings and methods other than the twin method (Plomin, 1981). One approach to measurement involves objective measures such as actometers to measure activity level (Plomin \& Foch, 1980; Saudino \& Eaton, 1991, in press). Another approach is to use ratings based on videotape observations in the laboratory or home (Goldsmith \& Campos, 1986; Matheny, 1989; Plomin et al., 1993). A variant of this approach is the use of ratings by testers following administration of developmental tasks. For example, the Infant Behavior Record (IBR) was developed by Nancy Bayley in order to assess temperament-like behavior seen during administration of the Bayley Scales of Infant Development (Bayley, 1969). In infancy, IBR ratings have shown reasonable and replicable patterns of genetic influence in twin studies (Goldsmith \& Gottesman, 1981; Matheny, 1980; Saudino, DeFries, \& Plomin, in press). Moreover, unlike parental ratings, twin analyses of the IBR yield results similar to those found in a sibling adoption analysis that compared resemblance of nonadoptive siblings and adoptive siblings (Braungart, Plomin, DeFries, \& Fulker, 1992). Although it is a narrow window through which testers view temperament, tester ratings have three advantages. First, unlike most parents, testers have experience with a broad range of children and thus have an adequate standard of comparison for ratings of children's temperament. Second, although the testing situation is a limited context in which to observe children's behavior, it is a standard situation that facilitates comparisons among children. Third, the testing situation can be somewhat stressful, which may enrich observations of certain temperament-like behaviors.

Although not previously used in genetic research on temperament, teachers also seem likely to be a useful source of information about temperament in middle childhood. The school environment is a much wider window both in terms of time and contexts than a test session of a few hours' duration upon which tester ratings are based. Like testers, teachers have experience with sufficient numbers of children to make relative comparisons about temperament. The validity of teacher ratings is supported by moderate correlations found across ratings by different teachers for temperament (Keogh, 1982) and problem behaviors (Achenbach, McConaughy, \& Howell, 1987).
Because the contexts of teacher and tester ratings are dissimilar, teacher and tester ratings are not expected to correlate highly. We are not aware of reported correlations for temperament, but for behavioral problems teacher and tester ratings correlate about .30 (Achenbach et al., 1987). Use of both teacher and tester ratings permits novel analyses of the genetic underpinnings of the situational specificity of temperament. An obvious question is whether the magnitude of genetic influence differs for teacher and tester ratings. A more subtle question involves the extent to which genetic effects on teacher ratings overlap with genetic effects on tester ratings. A transsituational view of temperament would predict that what is in common between teacher and tester ratings is heritable, even though the phenotypic correlation between teacher and tester ratings may be modest. In contrast, a contextual view of temperament would be compatible with finding independent genetic influences on temperament as seen by teachers and testers. Of course, any combination of these two extreme positions is possible for different dimensions of temperament. This issue can be addressed using multivariate genetic analyses which focus on genetic and environmental contributions to the covariance between variables-in this case, teacher and tester ratings of temperament-rather than the variance of each variable considered separately (Martin \& Eaves, 1977; Plomin \& DeFries, 1979).

The purpose of the present study is to investigate genetic influence at 7 years of age using teacher as well as tester ratings of temperament and the sibling adoption design of the Colorado Adoption Project (CAP; DeFries, Plomin, \& Fulker, 1994). Because tester ratings of temperament show genetic influence in sibling adoption analyses as well as in twin analyses in infancy and early childhood, we hypothesized that, unlike parent ratings, genetic influence would emerge from our sibling adoption analyses. Although teacher ratings have not been used previously in genetic research on temperament, we predicted that teacher ratings would also yield evidence of some genetic influence, as suggested by preliminary analyses of the CAP sibling data (Schmitz, 1994). Finally, although multivariate genetic analyses of the covariance between teacher and tester ratings have not been reported previously, we hypothesized that the covariance between these two sources of information about temperament is due at least in part to heritable influences. 


\section{Method}

Sample.-The Colorado Adoption Project (CAP) is an ongoing, prospective longitudinal study of behavioral development that assesses adoptive and matched nonadoptive children with a multitude of developmental measures. The CAP sample and selection procedures are described elsewhere in detail (Plomin \& DeFries, 1985; Plomin, DeFries, \& Fulker, 1988; DeFries et al., 1994). Briefly, the adopted children were separated from their biological mothers at the average age of 4 days and were placed in their adoptive homes at the average age of 28 days. Nonadoptive families were matched to adoptive families on the basis of the child's age and gender as well as the number of children in the family and the father's educational and occupational status.

The present analyses include nearly complete data for the entire CAP sibling sample at age 7 . For teacher ratings, the numbers of adoptive and nonadoptive sibling pairs range from 53 to 69 and 54 to 79 , respectively, depending on the temperament scale. For tester ratings, the sample sizes range from 55 to 83 adoptive sibling pairs and 59 to 99 nonadoptive sibling pairs (see Table 1).

Procedure and measures.-For each child, teacher and tester ratings of temperament were obtained using the Colorado Childhood Temperament Inventory (CCTI; Rowe \& Plomin, 1977). The CCTI is an amalgamation of the EAS temperament dimensions (Buss \& Plomin, 1975, 1984) and the nine dimensions of temperament postulated in the New York Longitudinal Study (Chess \& Thomas, 1984). Because the CCTI was originally designed as a parent rating measure, the questions were modified slightly for the school and test situations. Four scales corresponding to the EAS temperaments were obtained for each measure: Emotionality, Activity, Sociability, and Attention Span/Persistence.

In the CAP, adopted and nonadopted probands are assessed annually, either in person or by telephone. The younger siblings of these children are tested under the same protocol when they were of the same age. On average, siblings were assessed approximately 2 years apart. In the spring of the child's first year of grade school (i.e., when the child is on average 7 years old), parents delivered the CCTI to the child's teacher, who was then asked to complete the questionnaire and return it by mail to the University of Colorado. The following summer, CAP children attended a full-day test session at the Institute for Behavioral Genetics, University of Colorado. This assessment included measures of cognitive abilities, motor development, personality, interests, and talents. Different testers rated the temperament of each child on the CCTI at the end of the 5-hour test session (i.e., no effort was made to have a sibling tested by the same tester who rated the proband some

TABLE 1

Sample Sizes Available for Descriptive Statistics (Upper Panel) and Sibling Pairs Available for Uni- and Bivariate Behavior Genetic Analyses (Lower Panel)

\begin{tabular}{|c|c|c|c|c|c|c|c|c|}
\hline \multirow[b]{3}{*}{ SCALE } & \multicolumn{4}{|c|}{ Probands } & \multicolumn{4}{|c|}{ SIBLINGS } \\
\hline & \multicolumn{2}{|c|}{ Teacher } & \multicolumn{2}{|c|}{ Tester } & \multicolumn{2}{|c|}{ Teacher } & \multicolumn{2}{|c|}{ Tester } \\
\hline & Adopted & Control & Adopted & Control & Adopted & Control & Adopted & Control \\
\hline Emotionality ............ & 181 & 196 & 148 & 163 & 69 & 84 & 74 & 81 \\
\hline 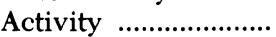 & 179 & 197 & 198 & 217 & 71 & 83 & 86 & 97 \\
\hline Sociability ................ & 155 & 165 & 198 & 216 & 66 & 70 & 86 & 98 \\
\hline \multirow[t]{4}{*}{ Attention span ........... } & . 181 & 201 & 198 & 217 & 71 & 85 & 86 & 98 \\
\hline & \multicolumn{4}{|c|}{ UNIVARIATE } & \multicolumn{4}{|c|}{ Bivariate } \\
\hline & \multicolumn{2}{|c|}{ Teacher } & \multicolumn{2}{|c|}{ Tester } & \multicolumn{2}{|c|}{ Teacher } & \multicolumn{2}{|c|}{ Tester } \\
\hline & Adopted & Control & Adopted & Control & Adopted & Control & Adopted & Control \\
\hline Emotionality ............. & 69 & 76 & 55 & 59 & 42 & 46 & 42 & 46 \\
\hline 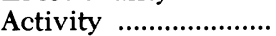 & 68 & 77 & 82 & 99 & 65 & 73 & 65 & 73 \\
\hline Sociability ................. & 53 & 54 & 81 & 99 & 50 & 53 & 50 & 53 \\
\hline Attention span .......... & 69 & 79 & 83 & 99 & 66 & 77 & 66 & 77 \\
\hline
\end{tabular}




\section{Child Development}

years previously). Internal consistencies of Emotionality are .90 for teacher and .79 for tester ratings, .93 and .81 for Activity, .89 for both teacher and tester ratings of Sociability, and .93 for both ratings of Attention Span/ Persistence (Cronbach's alpha).

Design.-The present study uses the sibling adoption design, which compares adoptive and nonadoptive sibling pairs to assess genetic and environmental contributions to teacher- and tester-rated temperament and to the covariance between teacher and tester ratings of temperament. Figure 1 depicts a path diagram of the basic model for a child's resemblance with its sibling. Unidirectional arrows represent latent genetic and environmental influences on the phenotype, whereas correlations are shown as double-headed arrows.

Under this model, phenotypic variation is assumed to be due to three latent variables: additive genetic effects $(A)$, environmental effects that are shared among siblings $(C$; e.g., shared parental behavior, attending the same school), and nonshared environmental effects that are unique to each sibling $(E$; e.g., illnesses or accidents as well as measurement error). In Figure 1, the path coefficients (i.e., $h, c$, and $e$ ) are standardized partial regressions that indicate the relative influence of the latent variables on the phenotype. The percentage of variance explained by a path is the square of its path coefficient.

The expected correlation between members of sibling pairs can be computed by summing the products of the paths that connect their phenotypes, following the rules of path analysis (Wright, 1934). For example, in Figure 1, the sibling correlation is computed as: $(h)\left(R_{\mathrm{G}}\right)(h)+(c)(c)$. The expression $R_{\mathrm{G}}$ denotes the genetic correlation be- tween siblings, that is, their degree of genetic relatedness. Full, nonadoptive siblings share, on average, $50 \%$ of their segregating genes and, thus, have a genetic correlation of .50. For adoptive siblings, $R_{\mathrm{G}}$ is zero since the siblings are biologically unrelated. Because members of nonadoptive and adoptive sibling pairs are reared together, they share at least some environmental influences. Therefore, the expected correlation between nonadoptive siblings is $.5 h^{2}+c^{2}$, indicating that the siblings share both genetic and environmental influences. In contrast, correlations between adoptive siblings are due only to $c^{2}$, shared environmental variance. Correlations between nonadoptive siblings that exceed those for adoptive siblings indicate genetic influences. Heritability $\left(h^{2}\right)$, the genetic effect size, can be estimated as twice the difference between the correlations for nonadoptive siblings and adoptive siblings. Similarly, the adoptive sibling correlation provides a direct estimate of shared environmental variance $\left(c^{2}\right)$.

This model requires two important assumptions. First, it is assumed that there is no selective placement, that is, that the adopted children were not placed with adoptive parents who are similar to their birth parents, which would increase the similarity of adoptive siblings and result in underestimates of $h^{2}$. It is also assumed that there is no assortative mating for the variable in question, such that spouse scores do not correlate more highly than would be expected by chance. Assortative mating would increase the similarity of nonadoptive siblings and would lead to overestimates of $h^{2}$. Previous analyses suggest that, for temperament, selective placement and assortative mating are not problematic for the CAP sample, since correlations between biological and adoptive parents as well as correlations

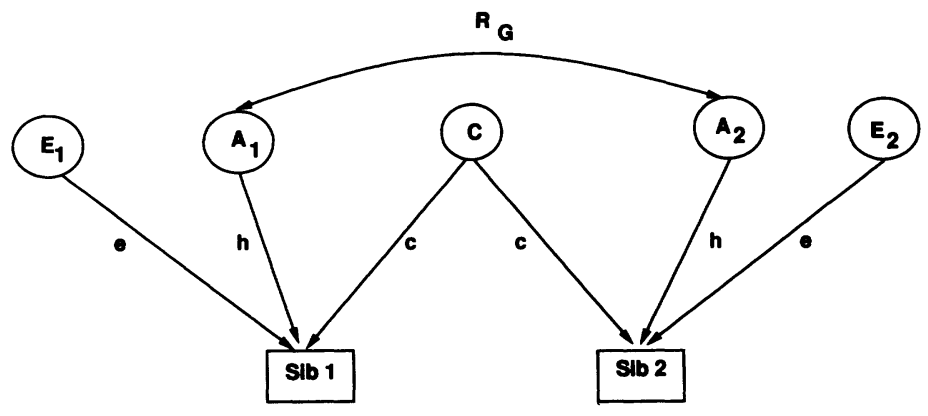

FIG. 1.-Path diagram depicting the correlation between siblings where $R_{\mathrm{G}}$ symbolizes the additive genetic correlation. Additive genetic $(A)$, shared $(C)$, and unique $(E)$ environmental influences on the observed behavior are shown (sibling adoption design). 
between mothers and fathers for all three groups (adoptive, biological, and control) are generally small and nonsignificant (Plomin et al., 1991; Schmitz, 1994).

Uni- and bivariate estimates of components of variance.-In addition to examining adoptive and nonadoptive sibling correlations, parameter estimates for the univariate case were obtained using the structural equation modeling program $\mathrm{Mx}$ (Neale, 1994), based on the model outlined above. These parameter estimates can be tested for their statistical significance by comparing a model with the parameter to a reduced model that constrains this parameter to be zero. The resulting change in $\chi^{2}$ and model fit is the test statistic for the parameter excluded from the reduced model.

The sibling adoption design can also be used to examine the degree to which genetic and environmental factors mediate the covariation between teacher and tester ratings for each of the four assessed temperament dimensions. The essence of genetic analysis of covariance is the cross-sibling correlation, that is, the correlation between one sibling's score for a teacher-rated temperament dimension and the other sibling's score for tester ratings of the same dimension. If the covariance between teacher and tester ratings of temperament is genetically mediated, nonadoptive cross-sibling correlations will exceed those for adoptive siblings.
In addition to examining cross-sibling correlations, we employed multivariate model-fitting procedures to test for genetic and environmental influences on the covariance between teacher and tester ratings of temperament. A bivariate Cholesky triangular decomposition model was fitted to observed covariance matrices using $\mathrm{Mx}$ (Neale, 1994). As illustrated in Figure 2, this model decomposes the phenotypic variance for teacher ratings and tester ratings into parts due to three factors that are common to teacher and tester ratings: additive genetic $\left(A_{t}\right)$, shared environmental $\left(C_{t}\right)$ and nonshared $\left(E_{t}\right)$ environmental contributions; and due to those three factors that are unique to tester ratings: again, additive genetic $\left(A_{\mathrm{r}}\right)$, shared environmental $\left(C_{\mathrm{r}}\right)$ and nonshared environmental $\left(E_{\mathrm{r}}\right)$ contributions. The three factors that are common to teacher and tester ratings $\left(A_{t}, C_{t}\right.$, and $\left.E_{t}\right)$ include variance specific to teacher ratings as well. The paths from the common factors to the phenotype for teacher ratings $\left(h_{t}, c_{t}, e_{t}\right)$ indicate the relative magnitude of genetic and environmental influences on teacher ratings of a particular temperament dimension. Squaring these path coefficients estimates the proportion of variance on teacher ratings that is due to genetic and environmental influence (i.e., $h^{2}, c^{2}, e^{2}$ ). The paths from the common factors to the phenotype for the tester ratings $\left(h_{\mathrm{rt}}, \mathrm{c}_{\mathrm{rt}}, \mathrm{e}_{\mathrm{rt}}\right)$ indicate the extent to which genetic and environmental influences

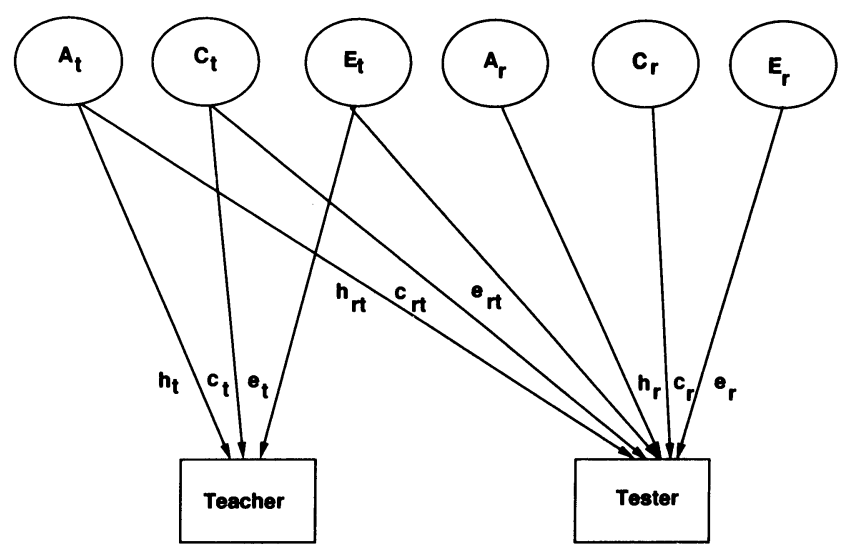

FIG. 2.-Path diagram depicting a bivariate Cholesky or triangular decomposition where $A_{\mathrm{t}}$ and $A_{\mathrm{r}}$ are the latent additive genetic influences on teacher and tester ratings, respectively, $C_{\mathrm{t}}$ and $C_{\mathrm{r}}$ correspond to the latent shared environmental influences, and $E_{\mathrm{t}}$ and $E_{\mathrm{r}}$ refer to the latent unique environmental influences. The relative strength of these influences on the observed phenotypic variance (standardized to unit variance) are shown by the path coefficients $h_{\mathrm{t}}, \mathrm{c}_{\mathrm{t}}$, and $e_{\mathrm{t}}$ for teacher ratings and by $h_{\mathrm{r}}, \mathrm{c}_{\mathrm{r}}$, and $e_{\mathrm{r}}$ for tester ratings. The path coefficients $h_{\mathrm{tr}}, \mathrm{c}_{\mathrm{tr}}$, and $e_{\mathrm{tr}}$ indicate the relative strength of the additive genetic, shared, and unique environmental influences on tester ratings that are due to influences on teacher ratings as well. 


\section{Child Development}

on teacher ratings are common to tester ratings. The paths from the three unique factors to the phenotype for tester ratings $\left(h_{r}, c_{r}, e_{r}\right)$ represent genetic and environmental influences on tester ratings that are independent of genetic and environmental influences on teacher ratings. The proportion of variance of tester ratings that is due to genetic or environmental influences is estimated by summing the squared path coefficient for the path leading from the common factor to the tester rating and the squared path coefficient leading from the unique factor to the tester rating (e.g., $h_{\mathrm{rt}}^{2}+h_{\mathrm{r}}^{2}$ ). The product of the genetic paths from $A_{t}$, the common genetic factor, to the teacher and tester phenotypes, i.e., $\left(h_{\mathrm{t}}\right)\left(h_{\mathrm{rt}}\right)$, estimates the genetic contribution to the phenotypic correlation between teacher and tester ratings. The order of variables included in this model is arbitrary; that is, modeling common factors for tester ratings and unique factors for teacher ratings will give identical results regarding the relative size of the variance components while path coefficients will differ. All parameter estimates (i.e., $h_{\mathrm{r}}^{2}, h_{\mathrm{t}}^{2}$ ) are standardized to sum to unity.

\section{Results}

Descriptive statistics. - Table 2 lists the means, standard deviations, and sample sizes, by adoptive status and gender, for teacher and tester ratings of temperament. These descriptive statistics are given for all adopted and nonadopted children, regardless of whether they have siblings or not. Siblings are not included in these calculations, since siblings in adoptive families could be either the biological child of the adoptive parents or a second adopted child.

To evaluate mean differences in our sample, $2 \times 2$ analyses of variance were conducted (adoptive vs. nonadoptive $\times$ gender). For teacher ratings each of the four scales consists of five items that are summed to give a scale score. For tester ratings, however, the number of items per scale varies, and an averaged score is therefore given. The sample sizes differ per scale, depending on the availability of ratings. Sample sizes for both descriptive statistics and subsequent behavior genetic analyses are given in Table 1.

Both teachers and testers rated adopted children, regardless of their gender, as more active and less attentive than nonadoptive children, Activity, $F(1,372)=5.69, p<.05$, for teachers and $F(1,411)=6.20, p<.05$, for testers, respectively; Attention Span, $F(1$, $378)=8.70, p<.01$, for teachers and $F(1$, $411)=8.41, p<.01$, for testers, respectively. Additionally, adoptive children were rated as more sociable by teachers, $F(1,316)$ $=4.20, p<.05$, and as more emotional by testers, $F(1,307)=9.08, p<.01$. Boys, regardless of their adoption status, were rated as being more emotional, $F(1,373)=4.30$, $p<.05$, and less attentive, $F(1,378)=13.13$, $p<.001$, by their teachers, and as more active by both teachers, $F(1,372)=8.24, p<$ .01 , and testers, $F(1,411)=12.42, p<.001$. All of these differences, however, were small and accounted for only $1.1 \%-2.9 \%$ of the observed variation. No significant gender $\times$ adoptive status interactions were found.

Phenotypic correlations between teacher and tester ratings, combining ratings of both adopted and nonadopted children as well as their siblings, are moderate and significant for three of the temperament dimensions: Attention Span, $r(521)=.29, p<.001$, Sociability, $r(439)=.26, p<.001$, and Activity, $r(512)=.19, p<.001$. Emotionality was the only scale for which the correlation between teacher and tester ratings was nonsignificant, $r(398)=.07, p>.05$.

Adoptive and nonadoptive sibling intraclass correlations for teacher and tester ratings of temperament are presented in Table 3. Sibling pairs who had been identified as bivariate outliers via Cook's D statistic have been excluded, even though the change in correlation was minimal. For both teachers and testers, the correlations for adoptive siblings are low and nonsignificant. In contrast, nonadoptive sibling correlations are significant for teacher and tester ratings of Activity and for tester ratings of Sociability. Thus, individual differences on these two measures may be due in part to genetic influences. In addition, teacher ratings of Emotionality may also be genetically influenced. Although neither the adoptive nor nonadoptive correlations for teacher ratings of Emotionality are significantly different from zero for this sample size, the correlation for nonadoptive siblings is significantly different from that for adoptive siblings.

Univariate components of variance.-Estimates of heritability and shared environmental variance derived from the univariate model are presented in Table 4. Consistent with our interpretation of sibling intraclass correlations, significant genetic influences were apparent for teacher ratings of Emo- 


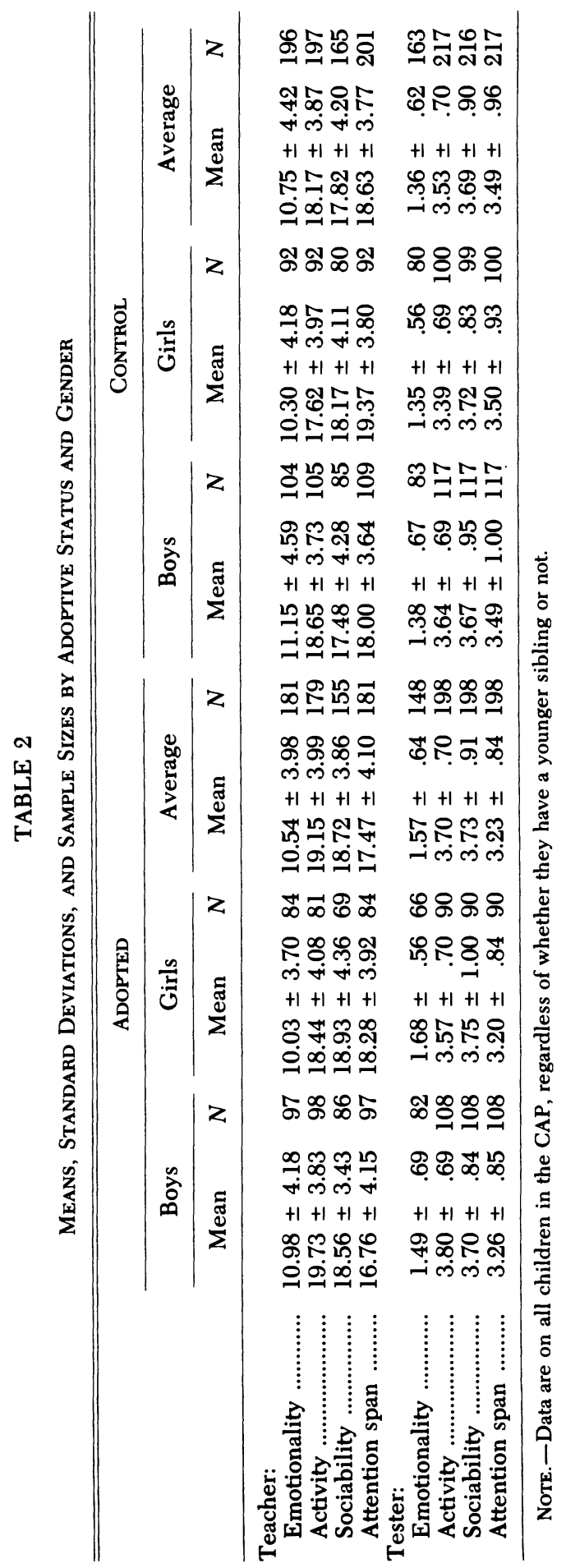


TABLE 3

Intraclass Sibling Correlations for Teacher and Tester Ratings of TEMPERAMENT ON THE CCTI

\begin{tabular}{|c|c|c|c|c|}
\hline & \multicolumn{2}{|c|}{ TEACHER } & \multicolumn{2}{|c|}{ Tester } \\
\hline & Adoptive & Nonadoptive & Adoptive & Nonadoptive \\
\hline 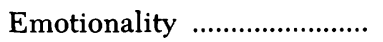 & $-.15(69)$ & $.18 \quad(78)$ & $.15(55)$ & $-.06 \quad(59)$ \\
\hline 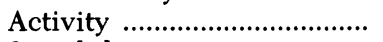 & $-.10(68)$ & $.37 *(77)$ & $.08(82)$ & $.27^{*} \quad(99)$ \\
\hline Sociability ............................... & $-.10(53)$ & $.03(54)$ & $-.06(81)$ & $.32 * *(99)$ \\
\hline 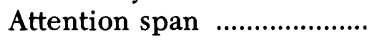 & $.15(69)$ & $.18 \quad(79)$ & $-.06(83)$ & $.10 \quad(99)$ \\
\hline
\end{tabular}

NOTE.-Numbers in parentheses indicate the number of sibling pairs on which the correlation is based. Sibling pairs who had been identified as bivariate outliers have been excluded, even though the change in correlation size was minimal.

${ }^{*} p<.05$.

$* * p<.01$

tionality and Activity $\left(h^{2}\right.$ of .34 and .74 , respectively) and tester ratings of Activity and Sociability ( $h^{2}$ of .39 and .64$)$. As in twin research using parental ratings of temperament, there was no evidence of significant shared environmental influences on any dimension of teacher- or tester-rated temperament.

Bivariate components of covariance.Table 5 lists the cross-sibling teacher-tester intraclass correlations for each temperament dimension. As noted in the table, each sib pair is used for both combinations, that is, sib1 teacher-sib2 tester and sib2 teachersibl tester, these being the two possible cross-correlations. However, if there are missing data, only one combination may occur. For example, if all data were present except for the teacher rating of sibl, then the first combination could not be computed. When no data are missing, then both combinations can be used to calculate the correlation. Unfortunately, the moderately low phe-

\section{TABLE 4}

Variance Components, Univariate Model

\begin{tabular}{|c|c|c|c|c|}
\hline \multirow[b]{3}{*}{ Parameter } & \multicolumn{4}{|c|}{ Measure } \\
\hline & \multicolumn{2}{|c|}{ Teacher } & \multicolumn{2}{|c|}{ Tester } \\
\hline & $h^{2}$ & $c^{2}$ & $h^{2}$ & $c^{2}$ \\
\hline Emotionality .......... & $.34 *$ & .00 & .01 & .08 \\
\hline Activity ................... & $.74 * *$ & .00 & $.39 *$ & .07 \\
\hline Sociability .............. & .04 & .00 & $.64^{* *}$ & .00 \\
\hline Attention span ...... & .07 & .13 & .19 & .00 \\
\hline
\end{tabular}

NoTE._Bivariate outliers have been excluded from the analyses.

$* p<.05$.

$* * p<.001$ notypic correlations between teacher and tester ratings increases the sample size needed to analyze cross-sibling correlations with sufficient power to detect genetic and environmental sources of covariance. With our sample, neither adoptive nor nonadoptive siblings demonstrated significant crosssibling correlations for any temperament dimension. However, a pattern of nonadoptive correlations that are greater than adoptive correlations for Activity and Sociability hints that genetic factors might be contributing to the covariance between teacher and tester ratings for these measures. Multivariate model-fitting procedures provide a more powerful analysis of genetic and environmental contributions to the covariance between teacher and tester ratings of temperament. Table 6 presents the model-fitting results for Emotionality, Activity, Sociability, and Attention Span, respectively. With the exception of Emotionality, the full bivariate model fit the data well for each temperament dimension. Asterisks indicate significant influences, that is, paths that could not be dropped from the model without resulting in a significant decrement in the fit of the model as indicated by a change in $\chi^{2}$.

Despite the poor fit of the bivariate model for Emotionality $\left(\chi^{2}(11)=55.75, p<\right.$ .01 ), the results shown in Table 6 are consistent with the interpretations based on the phenotypic sibling and cross-sibling correlations. For teacher ratings, the heritability of Emotionality is estimated as .21 (i.e., $.46^{2}$ ), whereas the heritability of tester rated Emotionality is .01 (i.e., $\left..11^{2}+.00^{2}\right)$. These heritabilities differ only slightly from those estimated with univariate model-fitting procedures. However, the heritability estimate for teacher ratings is not significant un- 
TABLE 5

Cross-Sibling Teacher-Tester Intraclass Correlations for CCTI TEMPERAMENT Dimensions

\begin{tabular}{|c|c|c|}
\hline & Adoptive & Nonadoptive \\
\hline Emotionality & $.11(197)$ & $-.03(135)$ \\
\hline Activity & $.00(144)$ & $.16(171)$ \\
\hline Sociability ...... & $-.11(129)$ & $.12(147)$ \\
\hline Attention span & $-.01(148)$ & $.03(174)$ \\
\hline
\end{tabular}

NOTE. - Numbers in parentheses indicate the number of sibling pairs on which the correlation is based; instead of using weighted averages, each sib pair is used for both combinations (sibl teacher-sib2 tester and sib2 teacher-sibl tester). Sibling pairs who had been identified as bivariate outliers have been excluded.

der the bivariate model. This is due to a reduction in sample size for the bivariate analysis-only sibling pairs with complete data for both teacher and tester ratings are included. As might be expected from the nonsignificant phenotypic correlation between teacher and tester ratings of Emotionality, none of the paths leading from the common genetic and environmental factors to the tester phenotype are significant. Thus, there is no significant genetic or environmental covariance between teacher and tester ratings for this temperament dimension.

For the dimension of Activity $\left(\chi^{2}(11)=\right.$ $13.45, p=.27)$, the bivariate and univariate models concurred in suggesting significant genetic influences on teacher and tester ratings. As shown in Table 6 and Figure 3, the bivariate model yields heritability estimates of $.74\left(.86^{2}\right)$ and $.27\left(.35^{2}+.38^{2}\right)$ for teacher and tester ratings of Activity, respectively. There were no significant shared environmental influences for either measure. As suggested by the pattern of cross-sibling intraclass correlations, there are significant genetic contributions to the phenotypic covariance between teacher and tester ratings of Activity. In Table 6, the parameter estimate for the path leading from the common genetic factor to the phenotype for tester ratings $\left(h_{\mathrm{rt}}\right)$ of Activity was significant and

TABLE 6

Parameter Estimates, Full Bivariate Model

\begin{tabular}{|c|c|c|c|c|}
\hline Parameter & Emotionality & Activity & Sociability & Attention Span \\
\hline$h_{t} \ldots \ldots \ldots \ldots \ldots \ldots \ldots$ & .46 & $.86^{*}$ & .13 & .29 \\
\hline$c_{t} \ldots \ldots \ldots \ldots \ldots \ldots \ldots \ldots$ & .18 & .02 & .11 & $.38^{*}$ \\
\hline$e_{t}$ & $.87^{*}$ & $.50^{*}$ & $.98^{*}$ & $.88^{*}$ \\
\hline 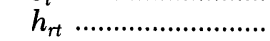 & .11 & $.35^{*}$ & $.90^{*}$ & .25 \\
\hline$c_{r t} \ldots \ldots \ldots \ldots \ldots \ldots \ldots \ldots$ & .29 & .33 & .08 & .00 \\
\hline$e_{r t} \quad \ldots \ldots \ldots \ldots \ldots \ldots \ldots \ldots \ldots$ & .20 & .32 & $.11^{*}$ & $.20^{*}$ \\
\hline$h_{r} \ldots \ldots \ldots \ldots \ldots \ldots \ldots \ldots \ldots$ & .00 & $.38^{*}$ & .00 & .39 \\
\hline$c_{r}$ & .00 & .00 & .00 & .00 \\
\hline$e_{r}$ & $.93^{*}$ & $.73^{*}$ & $.41^{*}$ & $.87^{*}$ \\
\hline \multicolumn{5}{|l|}{ Teacher: } \\
\hline$h^{2} \ldots \ldots \ldots \ldots \ldots \ldots \ldots$ & .21 & $.74^{*}$ & .02 & .08 \\
\hline$c^{2}$ & .03 & .00 & .01 & $.15^{*}$ \\
\hline$e^{2} \ldots \ldots \ldots \ldots \ldots \ldots \ldots \ldots \ldots$ & $.76^{*}$ & $.26 *$ & $.97^{*}$ & $.77^{*}$ \\
\hline \multicolumn{5}{|l|}{ Tester: } \\
\hline .................. & .01 & $.27^{*}$ & $.81^{*}$ & .21 \\
\hline$c^{2} \ldots \ldots \ldots \ldots \ldots \ldots \ldots \ldots \ldots \ldots \ldots \ldots$ & .08 & .11 & .01 & .00 \\
\hline$e^{2} \ldots \ldots \ldots \ldots \ldots \ldots \ldots \ldots \ldots$ & $.91^{*}$ & $.63^{*}$ & $.18^{*}$ & $.79^{*}$ \\
\hline
\end{tabular}

Note. $-h_{t}, c_{t}$, and $e_{t}$ refer to genetic and environmental influences on teacher ratings; $h_{r t}$, $c_{r t}$, and $e_{r t}$ refer to genetic and environmental influences on tester ratings that are shared with teacher ratings; and $h_{r}, c_{r}$, and $e_{r}$, refer to genetic and environmental influences that are unique to tester ratings (see Fig. 2). $h^{2}, c^{2}$, and $e^{2}$ refer to the parts of the observed variation that is due to genetic, shared, and unique environmental influences, respectively. Those parameters that are included in a reduced model, based on parsimony and fit, are marked with an asterisk. 


\section{Child Development}

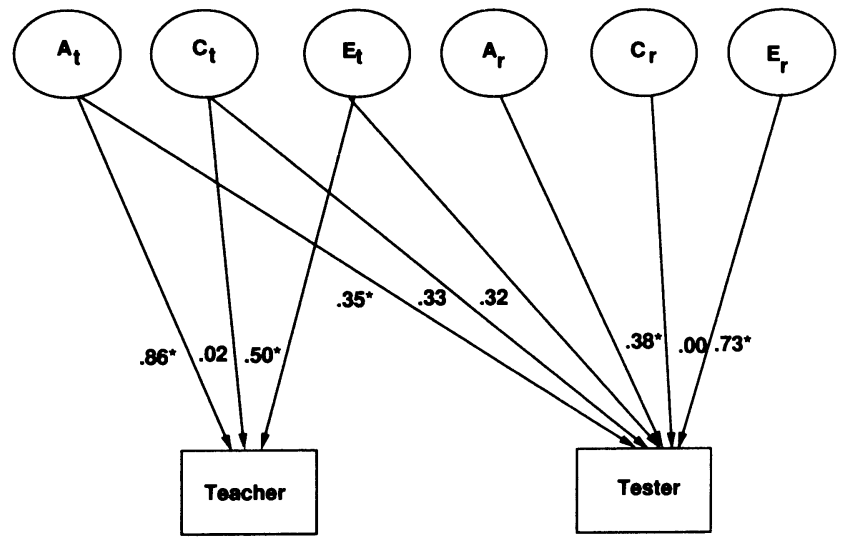

FIG. 3.-Bivariate model-fitting results for Teacher and Tester Ratings of Activity on the CCTI (full model with $\left.\chi^{2}(11)=13.45, p=.27\right)$. Asterisks indicate significant path loadings $(p<.05)$.

could not be dropped from the model. Fortysix percent of the genetic variance in tester ratings is shared with teacher ratings (i.e., $\left..35^{2} /\left[.35^{2}+.38^{2}\right]\right)$.

The bivariate results for Sociability (see Table $6 ; \chi^{2}(11)=16.33, p=.13$ ) are also consistent with the univariate analyses of teacher and tester ratings. Only tester ratings of Sociability displayed significant genetic influences $\left(h^{2}=.81\right)$. Once again, shared environmental influences were not significant for teacher or tester ratings. Although the path leading from the common genetic factor to the phenotype for tester ratings of Sociability is large, it does not contribute substantiantially to the correlation between teacher and tester ratings $(r=.90 \times .13=.12)$ and thus could be dropped from the model without significantly affecting the fit (i.e., it is nonsignificant). Thus, there does not appear to be significant genetic covariance between teacher and tester ratings of Sociability. Testing this result by reversing the model to allow for unique additive genetic factors for the teacher rather than tester ratings, neither the common nor unique genetic paths loading on teacher ratings were significant. This is expected because the heritability estimates for teacher ratings of Sociability derived from the univariate and bivariate models are both near zero. If teacher-rated Sociability is not genetically influenced, then the covariance between teacher and tester ratings must be due to environmental factors. Indeed, as there is no significant covariance between teachers and testers due to the shared environment $(r=.08 \times .11=$ $.01)$, only nonshared environmental influences contribute significantly to the pheno- typic covariance between teacher and tester ratings; therefore, the $e_{\text {rt }}$ path cannot be omitted from the reduced model.

The bivariate model for Attention Span (see Table $6 ; \chi^{2}(11)=13.45, p=.27$ ) yielded nonsignificant heritability estimates for teacher and tester ratings $\left(h^{2}=.08\right.$ and .21 , respectively); in contrast, teacher ratings displayed small, but significant, shared environmental influences $\left(c^{2}=.15\right)$. The path $\left(e_{\mathrm{rt}}\right)$ leading from $E_{\mathrm{t}}$ to the tester phenotype indicates that nonshared environmental influences contribute significantly to the phenotypic covariance between teacher and tester ratings of Attention Span. However, the genetic contribution to phenotypic covariance between teachers and testers is nonsignificant.

\section{Discussion}

Unlike parental ratings of temperament (Plomin et al., 1991), teacher and tester ratings of temperament yield evidence for genetic influence in this first sibling adoption study in middle childhood. Activity shows significant genetic influences for both teacher and tester ratings. Significant genetic influence also emerged for tester ratings of Sociability and for teacher ratings of Emotionality. Attention Span showed no genetic influence.

Although the sample size does not yield sufficient power to detect statistically significant differences in heritability, it is interesting to speculate about this pattern of results. Activity level is considered in most theories of temperament (Goldsmith et al., 1987) and was the most heritable tempera- 
mental dimension in this study. Activity shows genetic influence in studies of mice (Plomin \& Saudino, 1994), in twin and adoption research using tester ratings (Braungart et al., 1992; Matheny, 1980; Saudino et al., in press), and in twin research using actometers (Saudino \& Eaton, 1991, in press). The present study adds to this evidence for significant genetic influence for both teacher and tester ratings at 7 years of age using the sibling adoption design, even though members of the sibling pairs were rated by different teachers and testers on average 2 years apart.

The suggestion of genetic influence for tester but not teacher ratings of sociability is at first surprising. Teachers might be expected to be better judges of children's sociability than testers, who see the children only in a one-on-one testing situation. However, this might serve as a clue for the differences in genetic results for teacher and tester ratings. Teachers rate gregariousness and other social responses with familiar persons because the teachers were not asked to rate the children until well into the school year, when both the teacher and the other students are familiar to the rated child. In contrast, testers rate children's social interactions with a stranger (i.e., the tester), which may be more a matter of shyness than sociability (Buss \& Plomin, 1984). An observational twin study of infants suggests that social responding to a stranger shows genetic influence whereas social responding to a familiar person does not (Plomin \& Rowe, 1979). A hypothesis for future research is that social responses to familiar figures may show less genetic influence than social interactions with strangers.

For emotionality, some genetic influence was suggested for teacher ratings but not for tester ratings. It seems reasonable to hypothesize that teachers have more opportunity to see children upset than do testers, whose job it is not to upset the children they test.

Attention span shows no significant genetic influence, either for teacher or tester ratings. Attention span is one component of impulsivity which was initially included as part of the emotionality-activity-sociabilityimpulsivity (EASI) temperament theory of Buss and Plomin (1975). However, in a review of research findings a decade later, they concluded that although evidence for the heritability of the EAS temperaments had strengthened during the decade, the picture had become no clearer for impulsivity and thus dropped the "I" from their EASI theory (Buss \& Plomin, 1984). The present results support this decision. The greater impact of shared environmental influences on this dimension of temperament also implies an intervention strategy that differs from those regarding other aspects of temperament, in that not only unique environmental influences are of importance.

The relation between heritability and the definition of temperament needs clarification. We agree with the general definition of temperament offered by Bates (1989) that temperament "consists of biologically rooted individual differences in behavior tendencies that are present early in life and are relatively stable across various kinds of situations and over the course of time." The biological roots that interest us are genetic factors, that is, DNA-based differences among individuals that are transmitted hereditarily. Other biological roots, like the endocrine or the nervous system, are of special interest to other researchers (Bates \& Wachs, 1994). Heritability is our attempt to limit what we mean by the term "biological roots." Personality traits that show no genetic influence-such as neonatal behavior (Riese, 1990) and low-arousal emotions such as smiling (Plomin, 1987)-are of less interest to us in this context, although such dimensions of behavior may be of great interest to others. If there can be no absolute definition of temperament, all that is important is for researchers to be clear about setting bounds on what they mean by temperament. This situation is not different from that of research on intelligence (McCall in Goldsmith et al., 1987) or other areas.

The present results are interesting in terms of nurture as well as nature. Genetic research on personality as assessed by selfreport questionnaire in adolescents and adults clearly attributes environmental variance to nonshared environment rather than shared environment (Plomin \& Daniels, 1987). A similar tentative conclusion appears to emerge from twin research using tester ratings, observations, and objective measures of children's temperament. However, twin studies have limited power to detect shared environmental influence because it is indicated by residual twin resemblance not attributable to genetic resemblance (Martin, Eaves, Kearsey, \& Davies, 1978). The sibling adoption design has much greater power to detect shared environmental influence because the resemblance of 
adoptive siblings directly estimates shared environmental influence (e.g., Plomin, Chipuer, \& Neiderhiser, 1994). Despite the power of this design, the results for teacher and tester ratings in the present study confirm the results of twin studies in suggesting that there is no significant shared environmental influence. The largest correlation for adoptive siblings (Table 3 ) is only .15, and model-fitting analyses (Table 4) yield nonsignificant estimates of shared environment-indeed, most of the estimates are at or near zero.

A novel question raised by the bivariate genetic analyses is the extent to which genetic influences on teacher ratings of temperament are linked to genetic influences on tester ratings. The answer is clear for activity, the only dimension of temperament that showed significant genetic influence for both teacher and tester ratings. Genetic factors are entirely responsible for the covariance between teacher and tester ratings, even though the teacher-tester phenotypic correlation is modest. In other words, what the teachers and testers see in common in children's activity can be entirely attributed to genetic factors. This supports a transsituational view of the genetic underpinnings of activity. However, even for activity, some significant genetic influence is unique to tester ratings. That is, even though the modest covariance between teacher and tester ratings can be explained entirely by genetic factors, significant genetic effects on tester ratings of activity are independent of teacher ratings. This latter finding supports a situational specificity view at the level of genetic etiology. With situational specificity we do not mean a sampling of different aspects of the school situation, like classroom and recess for the school situation but, rather, the different quality of the school setting versus the laboratory setting.

Situational specificity of genetic influence is obvious for Sociability and Emotionality because genetic influence is significant only for tester ratings of sociability and only for teacher ratings of emotionality. Because genetic influence does not contribute to both teacher and tester ratings for these traits, it is not possible for genetic influence to account for the covariance between teacher and tester ratings. Moreover, for emotionality, the phenotypic correlation between teacher and tester ratings was nonsignificant. Together these findings suggest that genetic influences are contextually bound to a greater extent than one would expect from reading the temperament literature. Our interpretation is not that there are "temperament genes" unique to different contexts but rather that different contexts provide different views of temperament and thus engage different genetic influences on processes relevant to each context.

The bivariate results are interesting as well from an environmental perspective. First, because shared environmental influence is of negligible importance for both teacher and tester ratings, it is not surprising that shared environmental factors contribute nothing to the phenotypic covariance between teacher and tester ratings of temperament. Second, nonshared environmental factors are responsible for the covariance between teacher and tester ratings for Attention Span. This finding implies that the etiology of what teachers and testers both see in relation to children's attention span has to do with events unique to the child that are not shared with the child's sibling. Although research on specific sources of nonshared environment have only begun, findings of this type may provide clues as to what these influences might be. A first guess might be that nonshared environmental influences are situationally specific, but the present findings suggest that, whatever they are, nonshared environmental influences on attention span show a transsituational effect that transcends the school and laboratory settings.

Although research using other methods and measures is needed to confirm these results, at the least they suggest the usefulness of teacher and tester raters for investigating genetic and environmental influences on temperament in middle childhood. Identical and fraternal twins have been added to the Colorado Adoption Project (CAP), which will make it possible to make direct comparison between the present sibling adoption results and twin study results when sufficient numbers of twins have been studied at 7 years of age.

This research leaves many more questions than answers. One question of special interest to us is how genetic and environmental influences will unfold during development through the transition to adolescence. Because the CAP children in the present study are being studied longitudinally at $9,10,11$, and 12 using the same measures, we will be able to explore this issue in the future. 


\section{References}

Achenbach, T. M., McConaughy, S. H., \& Howell, C. T. (1987). Child/adolescent behavioral anc emotional problems: Implications of crossinformant correlations for situational specificity. Psychological Bulletin, 101, 213-232.

Bates, J. E. (1989). Concepts and measures of temperament. In G. A. Kohnstamm, J. E. Bates, \& M. K. Rothbart (Eds.), Temperament in childhood (pp. 3-26). Wiley: New York.

Bates, J. E., \& Wachs, T. D. (Eds.). (1994). Temperament: Individual differences at the interface of biology and behavior. Washington, DC: American Psychological Association.

Bayley, N. (1969). Manual for the Bayley Scales of Infant Development. New York: Psychological Corp.

Braungart, J. M., Plomin, R., DeFries, J. C., \& Fulker, D. W. (1992). Genetic influence on tester-rated infant temperament as assessed by Bayley's Infant Behavior Record: Nonadoptive and adoptive siblings and twins. $D e-$ velopmental Psychology, 28, 40-47.

Buss, A. H., \& Plomin, R. (1975). A temperament theory of personality development. New York: Wiley-Interscience.

Buss, A. H., \& Plomin, R. (1984). Temperament: Early developing personality traits. Hillsdale, NJ: Erlbaum.

Chess, S., \& Thomas, A. (1984). Origins and evolution of behavior disorders: Infancy to early adult life. New York: Brunner/Mazel.

DeFries, J. C., Plomin, R., \& Fulker, D. W. (1994). Nature and nurture during middle childhood. Oxford: Blackwell.

Goldsmith, H. H., Buss, A. H., Plomin, R., Rothbart, M. K., Thomas, A., Chess, S., Hinde, R. A., \& McCall, R. B. (1987). Roundtable: What is temperament? Four approaches. Child Development, 58, 505-529.

Goldsmith, H. H., \& Campos, J. J. (1986). Fundamental issues in the study of early temperament: The Denver Twin Temperament Study. In M. E. Lamb, A. L. Brown, \& B. Rogoff (Eds.), Advances in developmental psychology (Vol. 4, pp. 231-283). Hillsdale, NJ: Erlbaum.

Goldsmith, H. H., \& Gottesman, I. I. (1981). Origins of variation in behavioral style: A longitudinal study of temperament in young twins. Child Development, 52, 91-103.

Keogh, B. K. (1982). Children's temperament and teachers' decisions. In R. Porter \& G. M. Collins (Eds.), Temperamental differences in infants and young children (Ciba Foundation Symposium 89). Pitman: London.

Martin, N. G., \& Eaves, L. J. (1977). The genetical analysis of covariance structure. Heredity, 38 , 79-95.
Martin, N. G., Eaves, L. J., Kearsey, M. J., \& Davies, P. (1978). The power of the classical twin study. Heredity, 40, 97-116.

Matheny, A. P. J. (1980). Bayley's Infant Behavior Record: Behavioral components and twin analyses. Child Development, 51, 1157-1167.

Matheny, A. P. J. (1989). Children's behavioral inhibition over age and across situations: Genetic similarity for a trait during change. Journal of Personality, 57, 1-21.

Neale, M. C. (1994). Mx: Statistical modeling (2d ed.). Richmond, VA: Medical College of Virginia, Department of Psychiatry.

Plomin, R. (1981). Heredity and temperament: A comparison of twin data for self-report questionnaires, parental ratings, and objectively assessed behavior. In L. Gedda, P. Parisi, \& W. E. Nance (Eds.), Progress in clinical and biological research, Twin research 3: Part B. Intelligence, personality, and development (pp. 269-278). New York: Alan R. Liss.

Plomin, R. (1986). Development, genetics, and psychology. Hillsdale, NJ: Erlbaum.

Plomin, R. (1987). Developmental behavioral genetics and infancy. In J. Osofsky (Ed.), Handbook of infant development (2d ed., pp. 363417). New York: Wiley-Interscience.

Plomin, R., Chipuer, H. M., \& Loehlin, J. C. (1990). Behavioral genetics and personality. In L. A. Pervin (Ed.), Handbook of personality: Theory and research. New York: Guilford.

Plomin, R., Chipuer, H. M., \& Neiderhiser, J. M. (1994). Behavioral genetic evidence for the importance of nonshared environment. In E. M. Hetherington, D. Reiss, \& R. Plomin (Eds.), Separate social worlds of siblings: Importance of nonshared environment on devel opment (pp. 1-31). Hillsdale, NJ: Erlbaum.

Plomin, R., Coon, H., Carey, G., DeFries, J. C., \& Fulker, D. W. (1991). Parent-offspring and sibling adoption analyses of parental ratings of temperament in infancy and childhood. Journal of Personality, 59, 705-732.

Plomin, R., \& Daniels, D. (1987). Why are children in the same family so different from each other? Behavioral and Brain Sciences, 10, $1-16$.

Plomin, R., \& DeFries, J. C. (1979). Multivariate behavioral genetic analysis of twin data on scholastic abilities. Behavior Genetics, 9, 505-517.

Plomin, R., \& DeFries, J. C. (1985). Origins of individual differences in infancy: The Colorado Adoption Project. Orlando: Academic.

Plomin, R., DeFries, J. C., \& Fulker, D. W. (1988). Nature and nurture during infancy and early childhood. Cambridge: Cambridge University Press.

Plomin, R., Emde, R. N., Braungart, J. M., 


\section{Child Development}

Campos, J., Corley, R., Fulker, D. W., Kagan, J., Reznick, J. S., Robinson, J., Zahn-Waxler, C., \& DeFries, J. C. (1993). Genetic change and continuity from 14 to 20 months: The MacArthur Longitudinal Twin Study. Child Development, 64, 1354-1376.

Plomin, R., \& Foch, T. T. (1980). A twin study of objectively assessed personality in childhood. Journal of Personality and Social Psychology, 39, 680-688.

Plomin, R., \& Rowe, D. C. (1979). A twin study of temperament in young children. Journal of Psychology, 97, 107-113.

Plomin, R., \& Saudino, K. J. (1994). Quantitative genetics and molecular genetics. In J. E. Bates \& T. D. Wachs (Eds.), Temperament: Individual differences at the interface of biology and behavior (pp. 143-171). Washington, DC: American Psychological Association.

$\rightarrow$ Riese, M. L. (1990). Neonatal temperament in monozygotic and dizygotic twin pairs. Child Development, 61, 1230-1237.

Rowe, D. C., \& Plomin, R. (1977). Temperament in early childhood. Journal of Personality Assessment, 41, 150-156.
Saudino, K. J., DeFries, J. C., \& Plomin, R. (in press). Tester-rated temperament at 14, 20, and 24 months: Environmental change and genetic continuity. British Journal of Developmental Psychology.

$\rightarrow$ Saudino, K. J., \& Eaton, W. O. (1991). Infant temperament and genetics: An objective twin study of motor activity level. Child Development, 62, 1167-1174.

Saudino, K. J., \& Eaton, W. O. (in press). Continuity and change in objectively assessed temperament: A longitudinal twin study of activity level. British Journal of Developmental Psychology.

Schmitz, S. (1994). Temperament and personality. In J. C. DeFries, R. Plomin, \& D. W. Fulker (Eds.), Nature and nurture during middle childhood (pp. 120-140). Oxford: Blackwell.

Stevenson, J., \& Fielding, J. (1985). Ratings of temperament in families of young twins. British Journal of Developmental Psychology, 3, 143-152.

Wright, S. (1934). The method of path coefficients. Annals of Mathematical Statistics, 5, 161-215. 